\title{
IGF-I Facilitates Cartilage Reconstruction by Regulating PI3K/AKT, MAPK, and NF-kB Signaling in Rabbit Osteoarthritis
}

\author{
Mohammad Amjad Hossain (i) I \\ Aravinthan Adithan' \\ Md Jahangir Alam ' \\ Spandana Rajendra Kopalli ${ }^{2}$ \\ Bumseok Kim' \\ Chang-Won Kang' \\ Ki-Chul Hwang ${ }^{3}$ \\ Jong-Hoon Kim' \\ 'College of Veterinary Medicine, \\ Biosafety Research Institute, Chonbuk \\ National University, Iksan-city, Jeollabuk- \\ Do, Republic of Korea; ${ }^{2}$ Department of \\ Integrative Bioscience and Biotechnology, \\ Sejong University, Gwangjin-gu, Seoul, \\ 05006, Republic of Korea; ${ }^{3}$ Institute for \\ Bio-Medical Convergence, College of \\ Medicine, Catholic Kwandong University, \\ Gangneung-si, Gangwon-do, Republic of \\ Korea
}

Purpose: The pathogenesis of osteoarthritis (OA) is characterized by joint degeneration. The pro-inflammatory cytokine interleukin (IL)- $1 \beta$ plays a vital role in the pathogenesis of $\mathrm{OA}$ by stimulation of specific signaling pathways like NF-kB, PI3K/Akt, and MAPKs pathways. The catabolic role of growth factors in the OA may be inhibited cytokineactivated pathogen. The purpose of this study was to investigate the potential effects of insulin-like growth factor-1 (IGF-1) on IL-1 $\beta$-induced apoptosis in rabbit chondrocytes in vitro and in an in vivo rabbit knee OA model.

Methods: In the present study, the OA developed in chondrocyte with the treatment of IL-1 $\beta$ and articular cartilage ruptures by removal of cartilage from the rabbit knee femoral condyle. After IGF-1 treatment, immunohistochemistry and qRT-PCR were identified OA expression with changes in MMPs (matrix metalloproteinases). The production of ROS (intracellular reactive oxygen species) in the OA was detected by flow cytometry. Further, the disease progression was microscopically investigated and pathophysiological changes were analyzed using histology. The NF- $\kappa \mathrm{B}, \mathrm{PI} 3 \mathrm{~K} / \mathrm{Akt}$ and P38 (MAPK) specific pathways that are associated with disease progression were also checked using the Western blot technique.

Results: The expression of MMPs and various apoptotic markers are down-regulated following administration of IGF-1 in a dose-dependent fashion while significantly upregulation of TIMP-1. The results showed that higher levels of ROS were observed upon treatment of chondrocytes and chondral OA with IL-1 $\beta$. Collectively, our results indicated that IGF-1 protected NF- $\mathrm{BB}$ pathway by suppression of PI3K/Akt and MAPKs specific pathways. Furthermore, the macroscopic and pathological investigation showed that it has a chondroprotective effect by the formation of hyaline cartilage.

Conclusion: Our results indicate a protective effect of IGF-1 against OA pathogenesis by inhibition of NF- $\mathrm{BB}$ signaling via regulation of the MAPK and PI3K/Akt signaling pathways and prevention of apoptosis by suppression of ROS production.

Keywords: insulin-like growth factor-1, chondrocyte, cartilage development, osteoarthritis, rabbit

\section{Introduction}

Osteoarthritis (OA) is a disorder characterized by joint pain and disability that is associated with deterioration in quality of life. Age, obesity, trauma, instability, bone mass, joint injury and developmental disease are common causes of OA. ${ }^{1}$ Chondrocytes play an important role in chondral osteogenesis and cartilage regeneration by synthesize extracellular matrix components, such as proteoglycans and
Correspondence: Jong-Hoon Kim College of Veterinary Medicine, Biosafety Research Institute, Chonbuk National University, 79 Gobong-ro, Iksan-city, Jeollabuk-Do, 54596, Republic of Korea Email jhkimI@jbnu.ac.kr 
collagen. ${ }^{2}$ The destructive structure and damaged articular cartilage is very slow healing because of cartilage noninnervated and non-vascular tissue. ${ }^{3}$

Inflammatory cytokines have a principle role in the pathogenesis of OA. ${ }^{4}$ Following a cartilage injury, the stimulation of catabolic influences such as post-inflammatory cytokines encompassing tumor necrosis factor $\alpha(\mathrm{TNF}-\alpha)$ and IL-1 $\beta$ are involved in the development of OA. ${ }^{5}$ Chondrocytes exposed to TNF- $\alpha$ and IL- $1 \beta$ are key mediators to release matrix metalloproteinases (MMPs), and inhibits the synthesis of extracellular matrix proteins in chondrocytes which are responsible for the degeneration of articular cartilage. ${ }^{6-8}$ The balance among MMPs and TIMPs (tissue inhibitors of metalloproteinases) are important for the regulation of pathogenesis of Matrix metalloproteinases like MMP-1 (interstitial collagenase), MMP-3 (stromelysin-1) and MMP-13 (collagenase 3) plays an essential part in osteoarthritis based on their capability to cleave components of the ECM in articular cartilage. ${ }^{9-11}$ At the time of osteoarthritis, several catabolic signaling pathways have also been exposed to orchestrate the expression of matrix metalloproteinases, containing NF- $\mathrm{\kappa B}$, phosphatidylinositol 3-kinase (PI3K)/Protein kinase B (AKT) and MAPKs (mitogen-activated protein kinases) signaling pathways. ${ }^{12,13}$ The activated MAP kinases stimulate transcriptional regulatory proteins and other kinases of protein and which is enhanced the inflammatory cytokine such as TNF- $\alpha$, IL-1, and MMPs production. ${ }^{14}$ The cytokines like IL-1 $\beta$ lead to activate PI3K/ AKT signaling when it binds to the cell surface receptor. Upon stimulation, the PI3K produces AKT phosphorylation which has exposed to have a synergistic impact on NF- $\mathrm{KB}$ signaling. The MMPs will upregulation during the activation of PI3K/ AKT signaling. ${ }^{15}$ The transcription factor of NF- $\mathrm{KB}$ shows a significant role in osteoarthritis pathogenesis and it stimulated by cytokine of pro-inflammatory when ECM destruction. $^{16}$

Currently, steroidal and non-steroidal anti-inflammatory drugs (NSAIDs) are used for the treatment of OA, but these treatments fail to reverse disease progression. ${ }^{17,18}$ Many methods like Mosaicplasty, autologous chondrocyte implantation, chondrocyte transplantation and micro fracture have been reported to relieve inflammation and recover damage of cartilage. ${ }^{19,20}$ A universally accepted technique for repairing damage to cartilage has not been identified. The significant cellular progress, such as survival, growth, differentiation and antagonize has the effect of inflammatory intermediaries by the influence of anabolic growth factors. $^{21}$
Insulin-like growth factor-1 (IGF-1) is the leading anabolic growth factor in cartilage and is important for structural maintenance via stimulation of cartilage matrix molecules. ${ }^{22-25}$ During cartilage destruction, pro-inflammatory cytokines like IL-1 $\beta$ have been shown to have catabolic effects. ${ }^{26}$ IGF-1 plays a primary role in articular cartilage, where it balances the synthesis of type II collagen and proteoglycans for chondrocyte regulation. ${ }^{27,28}$ Recent studies revealed that IGF-1 protects chondrocytes from apoptosis. ${ }^{29-31}$ The impact of IGF-1 on PI3K/AKT, MAPK, and NF-kB signaling pathway has not been clearly elucidated. For this reason, we are interested in investigating the role of IGF-1 in these signaling pathways in chondrocytes (in vitro) and the rabbit model during OA progression. The aim of this study is to assess the effect of intra-articular injection of IGF-1 on the regeneration of chondrocytes in the femoral condyle and the anti-apoptotic effect of IGF-1 via downregulation of pro-inflammatory cytokine signaling in articular cartilage in OA.

\section{Materials and Methods Animal Study}

New Zealand female white rabbits (12 weeks old, weighing $3.5 \pm 0.2 \mathrm{~kg}, \mathrm{~N}=40$ ) were obtained from Koatech (Seoul, Korea). The animals were fed a normal diet and given water ad libitum. The animal room was maintained at $24 \pm 2^{\circ} \mathrm{C}$ with air conditioning under a $12 \mathrm{~h}$ light/ 12 $\mathrm{h}$ dark cycle. All surgical experiments were approved by the Chonbuk National University Animal Ethical Care and Use Committee (CBNU-2018-112). The guideline for laboratory animals of Internal Animal Care and Use Committee (IACUC) on Chonbuk National University.

\section{Chondrocyte Isolation and Culture}

Rabbit articular chondrocytes were collected from the knee cartilage of 12-week-old New Zealand female white rabbits. Briefly, cartilage slices were digested with $0.25 \%$ trypsin (Lonza, Belgium) for 30 minutes and then incubated for 4-6 $\mathrm{h}$ in Dulbecco's modified Eagle's medium/F-12 (DMEM/ F-12; Gibco, Grand Island, NY) with $0.2 \%$ type II collagenase (Gibco, USA) at $37^{\circ} \mathrm{C}$ in a shaking incubator. The chondrocytes were re-suspended after centrifugation and cultured in $25 \mathrm{~cm}^{2}$ culture flasks in complete DMEM/F12 with 10\% FBS (Gibco, USA) and 1\% antibiotic/antimycotic solution (Sigma-Aldrich, USA) in $5 \% \mathrm{CO}_{2}$ at $37^{\circ} \mathrm{C}$. The culture media was changed every other day. For in vivo studies, the cells were stored at $-80^{\circ} \mathrm{C}$ for later use. 


\section{Experimental Design of in vitro and in vivo Studies}

To investigate the effect of IGF-1 on IL- $1 \beta$-induced chondrocytes, cells were plated in a 6-well plate at a density of $5 \times 10^{6}$ cells/well. The cells were pretreated for $1 \mathrm{~h}$ with various concentrations of IGF-1 (10, 30, and $100 \mathrm{ng} / \mathrm{mL})$ before the addition of IL-1 $\beta(10 \mathrm{ng} / \mathrm{mL})$ and further incubation for $24 \mathrm{~h}$. Diclofenac $(50 \mu \mathrm{g} / \mathrm{mL})$ served as a positive control. For the in vivo study, the rabbits were randomly assigned to six groups $(n=6)$ as follows: 1$)$ normal control (N/C): articular cartilage was exposed and closed; 2) chondrectomy (Ch.tomy): articular cartilage was damaged but received no treatment; 3) 0.1 IGF-1: treated with $0.1 \mu \mathrm{g} / \mathrm{kg}$ IGF-1 for 10 days (intra-articularly); 4) 0.3 IGF-1: treated with $0.3 \mu \mathrm{g} / \mathrm{kg}$ IGF-1 for 10 days (intraarticularly); 5) 1.0 IGF-1: treated with $1.0 \mu \mathrm{g} / \mathrm{kg}$ IGF-1 for 10 days (intra-articularly); and 6) diclofenac (positive control): treated with $5 \mathrm{mg} / \mathrm{kg}$ diclofenac for 10 days (intramuscularly).

In detail, after sedation, the animals were placed on the operating table in a supine position. The animals were kept anesthetized under $3 \%$ isoflurane in oxygen during the surgery by a face mask. Before surgery, the right knee was sterilized with $70 \%$ alcohol, and $10 \%$ betadine solution. After exposing the right knee femoral condyle with a medial para-patellar incision, cartilage was removed using a surgical blade from the trochlear surface. The skin and tissues were sutured with polyglactin $2 / 0$ suture material. All treatments commenced 2 weeks after surgery.

\section{Real-Time PCR}

To quantify mRNA levels of OA and apoptosis-related gene expression, total RNA was extracted from the cells for in vitro and cartilage for in vivo according to the manufacturer's instructions (iNtRON Biotechnology, South Korea). cDNA was synthesized from $500 \mathrm{ng}$ of total RNA as a template using a cDNA synthesis kit (iNtRON Biotechnology, South Korea). Gene expression was quantified using SYBR green real-time PCR master mix (TOYOBO, Japan) and amplified under the following conditions: $2 \mathrm{~min}$ at $95^{\circ} \mathrm{C}, 20 \mathrm{~s}$ at $95^{\circ} \mathrm{C}$, and $20 \mathrm{~s}$ at $58^{\circ} \mathrm{C}$, for 40 cycles. The primer sequences used for PCR are shown in Table 1. Expression was evaluated in triplicate for each gene to reduce processing error. Using the $2^{-\Delta \Delta \mathrm{Ct}}$ method, relative gene expression was evaluated by normalizing target gene expression to glyceraldehyde-3-phosphate dehydrogenase (GAPDH) expression.

\section{Reactive Oxygen Species}

Reactive oxygen species (ROS) production was analyzed with a ROS detection kit with CellROX Green reagent (C10444, Invitrogen) from Life Technologies (made in the USA) according to the manufacturer's instructions. Chondrocytes were treated with various doses of IGF-1 for $1 \mathrm{~h}$, stimulated with IL-1 $\beta$ for $24 \mathrm{~h}$, then washed twice with PBS and incubated with $5 \mu \mathrm{M}$ CellROX Green reagent in $\mathrm{PBS}$ at $37^{\circ} \mathrm{C}$ for $60 \mathrm{~min}$ in the dark. After washing with PBS, fluorescence was measured immediately using flow cytometry (BD Accuri). Chondrocytes from rabbits after sacrifice at 4 and 8 weeks were used for in vivo analysis.

\section{Macroscopic Assessment}

The depth of destruction in articular cartilage was evaluated according to the measures described by Pelletier et $\mathrm{a}^{32}$ using a four-point scale $(0=$ normal-appearing surface, $1=$ negligible fibrillation or a minor yellowish discoloration of the surface, 2 = destruction spread out into the superficial or central layers only, $3=$ destruction that spread into the deep layers, and $4=$ destruction that spread to the subchondral bone). After 4 and 8 weeks, the animals were sacrificed by an overdose of sodium pentobarbital (IV) and the articular cartilage on the

Table I For qRT-PCR Study of Primer

\begin{tabular}{|l|l|l|}
\hline Genes & Forward & Reverse \\
\hline MMP-I & 5-CAGGAGCCTTCCCAAGAGGAA-3 & 5-CTTGTCTCTTGCATATCAGGATGATG-3 \\
MMP-3 & 5'-ACACCGGATCTGCCAAGAGA-3' & 5'-CTGGAGAACGTGAGTGGAGTCA-3' \\
MMP-I3 & 5'-CAGATGGGCATATCCCTCTAAGAA-3' & 5'-CCATGACCAAATCTACAGTCCTCAC -3 \\
TIMP-I & 5'-CAACTGCGGAACGGGCTCTTG-3' & 5'-CGGCAGCGTAGGTCTTGGTGAA -3' \\
Caspase 3 & 5'-GTGGCATCGAGACAGACAGT-3' & 5'-CCTCCTCCGAATTTCGCCA-3' \\
BAX & 5'-TATTATGGGCTGGACGCTGG-3' & 5'-CCAAGATGGTCAGCGTTTGC-3' \\
TNF-a & 5'-GACCACGTAGCCGTGTTCAG-3' & 5'-GGGCTCCACATTGCAGAGAA-3' \\
GAPDH & 5'-CTATAAATTGAGCCCGCAGC-3' & 5'ACCAAATCCGTTGACTCCG3' \\
\hline
\end{tabular}


femoral condyles in the right knee joint was opened for macroscopic evaluation. A greater score indicates more damage to the cartilage.

\section{Histological Findings}

For histological study after macroscopic observation, cartilage specimens from the destructive femoral area were fixed in a $10 \%$ buffered formalin solution (Sigma-Aldrich, USA) and decalcified with $8 \%$ formic acid and $8 \% \mathrm{HCl}$. Cartilage specimens were embedded in paraffin and sample sliced into 5- $\mu \mathrm{m}$ sections. Hematoxylin-eosin (HE, (Sigma-Aldrich, USA) and Masson (Scytek Lab.USA) stain Study after Paraffin specimens were dehydration and for glycosaminoglycan GAG) secretion bearings by safranin O (Sigma, USA). According to Mankin et al, the rigorousness of the OA destruction was categorized using the histologic standards (Table 2) based on structural variations (scale range 0 6 ), cellular variations (scale range $0-3$ ), damage of safranin $\mathrm{O}$ staining (scale range $0-4$ ) and tidemark integrity (scale range $0-1$ ) by 3 independent researchers. ${ }^{33}$

To carry out the immunohistochemical analysis, MMP-1 expression was measured by using vectastain $\mathrm{ABC}$ kit (Vector Lab.In., USA) according to the manufacturer's protocol. After de-paraffin Cartilage specimens and Cells (in vitro) were washed in PBS and for deactivating endogenous peroxidase action by the use of $3 \%$ Hydrogen peroxide $\left(\mathrm{H}_{2} \mathrm{O}_{2}\right)$ for $20 \mathrm{~min}$

Table 2 Mankin Score (Histological Evaluation)

\begin{tabular}{|c|c|c|}
\hline Score & Classification & Category \\
\hline 0 & Normal & Structural \\
\hline 1 & Irregularities Surface & \\
\hline 2 & Pannus Irregularities & \\
\hline 3 & Fissures into transitional zone & \\
\hline 4 & Fissures into emmitting zone & \\
\hline 5 & Fissures into calcified zone. & \\
\hline 6 & Complete disorganization & \\
\hline 0 & Normal & Cell \\
\hline 1 & Diffuse hypercellularity & \\
\hline 2 & Cloning & \\
\hline 3 & Hypocellularity & \\
\hline 0 & Normal & Safranin-O staining \\
\hline 1 & Slight reduction & \\
\hline 2 & Moderate reduction & \\
\hline 3 & Severe reduction & \\
\hline 4 & No dye noted & \\
\hline 0 & Normal & Tidemark integrity \\
\hline I & Disruption & \\
\hline
\end{tabular}

at room temperature with shaking. After blocked primary antibody (dilution 1:150), were incubated overnight at $4^{\circ} \mathrm{C}$ and then biotinylated second antibody horseradish peroxidase incubation 1:20 hours at RT. Afterward, before counterstaining with hematoxylin the specimens and cells were visualized until brown color with DAB kit (Thermo Scientific, USA) at dark condition. Eventually, cells were serially dehydrated and mounted. The intensity of MMP-1 staining and images were observed with an inverted contrast microscope (Zeiss Corporation, Germany) at a fixed 200x magnification.

\section{Western Blotting}

Proteins were extracted from chondrocyte (in vitro) and cartilage (in vivo) with cell lysis buffer (Pro-Prep, Intron Biotechnology, Korea) and protein concentration was measured using a BCA kit (Thermo Scientific, USA). The PVDF membrane that contained the protein was blocked with $1 \%$ (w/v) skim milk in Tris-buffered saline with Tween-20 (TBST) and then incubated overnight with primary antibodies against NF- $\mathrm{B}$ (1:500), Akt (1:500), p-Akt (1:1000) (Abcam, UK), P-p65 (1:1000), P38 (1:1000), and p-P38 (1:800) (Cell Signaling, MA, USA) at $4^{\circ} \mathrm{C}$. $\beta$-actin was used as a loading control. HRP-conjugated secondary antibody (Cell Signaling, MA, USA) was then added for $2 \mathrm{~h}$, and the membrane was washed with PBS. Specific proteins were identified on the immunoblots with Lumi pico solution (DoGen, Korea) and images of the blots were taken with a ImageQuant LAS-500 image analyzer (GE Healthcare, Sweden). Band quantification and analysis were performed using Image J software (ver. 1.49).

\section{Statistical Analysis}

Data are expressed as mean \pm standard deviation. Statistical significance was assessed using analysis of variance (ANOVA) followed by Tukey's multiple comparison tests. Statistical significance was defined as $p<0.05$. All in vitro experiments were performed in triplicate and the results are mean values of three independent experiments.

\section{Results}

\section{Impact of IGF-I on Chondrocyte Immunohistochemistry in vitro}

MMP1 protein levels in chondrocytes following various treatments were analyzed using immunohistochemical techniques. The results revealed that IL-1 $\beta$ treatment significantly upregulated the expression of MMP1 (observed as intense staining) compared with control treatment in 
chondrocytes. However, administration of IGF-1 significantly reduced MMP1 levels dose-dependently (Figure 1A).

\section{Impact of IGF-I on TIMP-I and MMPs in vitro}

After treatment with IGF-1, the gene-level of TIMP-1, MMP13, MMP-3, and MMP-1 were detected in chondrocytes by performed qRT-PCR. IGF-1 treatment increased TIMP-1 gene expression and protected high levels of MMP-13, MMP-3, and MMP-1 in chondrocytes dose-dependently. On the other hand, chondrocytes stimulated with IL- $1 \beta$ exhibited only TIMP-1 gene downregulation and enhancement of MMP-13, MMP-3, and MMP-1 gene expression compared with normal control (Figure 1B). MMP1 protein expression levels were also in line with these results.

\section{Impact of IGF-I on ROS Production in vitro}

Reactive oxygen species (ROS) have a vital role in the inflammatory process. The effect of IGF-1 on intracellular
ROS secretion in IL-1 $\beta$-induced chondrocytes was investigated. Intracellular ROS generation was greater in the IL-1 $\beta$ treated group $(76.7 \pm 6.2 \%)$. IGF-1 treatment dosedependently downregulated intracellular ROS secretion by $54.2 \pm 3.6 \%, 46.3 \pm 2.3 \%$, and $38.1 \pm 1.9 \%$ at doses of IGF- 1 10,30 , and $100 \mathrm{ng} / \mathrm{mL}$ respectively (Figure $1 \mathrm{C}$ ).

\section{Impact of IGF-I on PI3K/Akt, NF- $\kappa B$, and MAPK Signaling in vitro}

To examine whether IGF-1 inhibits IL-1 1 -induced damage in chondrocytes, we investigated the activity of the PI3K/ Akt, NF-kB, and MAPK signaling pathways using Western blot analysis. IGF-1 dose-dependently down-regulated p-Akt/Akt, P-p65/NF-kB, and p-P38/P38, whereas IL-1 $\beta$ treatment up-regulated the proteins (Figure $2 \mathrm{~A}$ and $\mathrm{B}$ ).

\section{Impact of IGF-I on TNF- $\alpha$, Caspase-3 and Bax in vitro}

Additional examination exposed that the pro-inflammatory factor TNF- $\alpha$ and the pro-apoptotic genes caspase 3 and

A

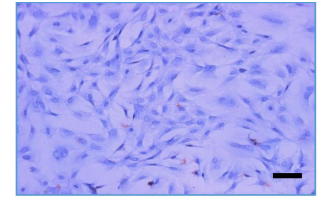

$\mathrm{N} / \mathrm{C}$

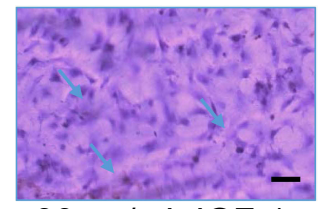

$30 \mathrm{ng} / \mathrm{mL}$ IGF-1

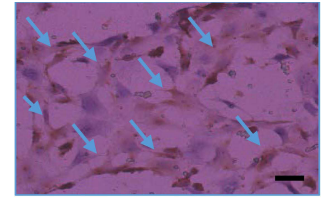

$\mathrm{IL}-1 \beta$

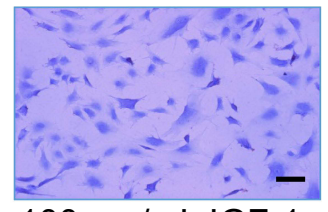

$100 \mathrm{ng} / \mathrm{mL}$ IGF-1

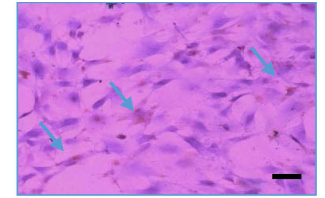

$10 \mathrm{ng} / \mathrm{mL}$ IGF-1

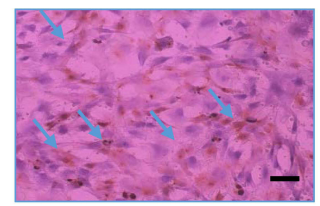

$50 \mu \mathrm{g} / \mathrm{mL}$ Diclofenac
B

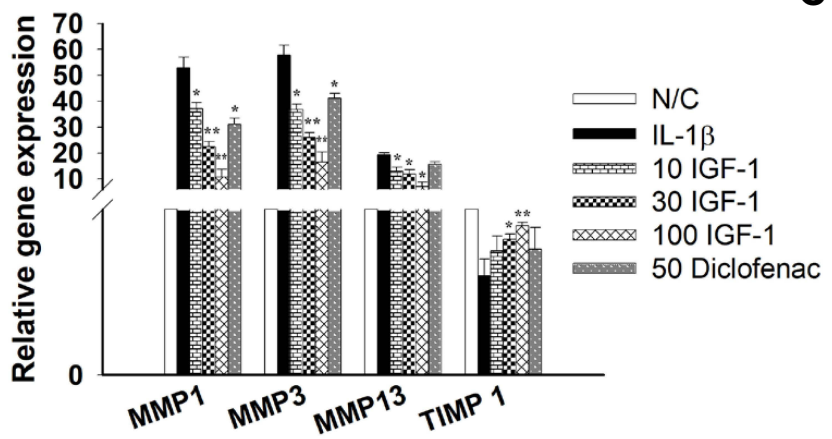

C

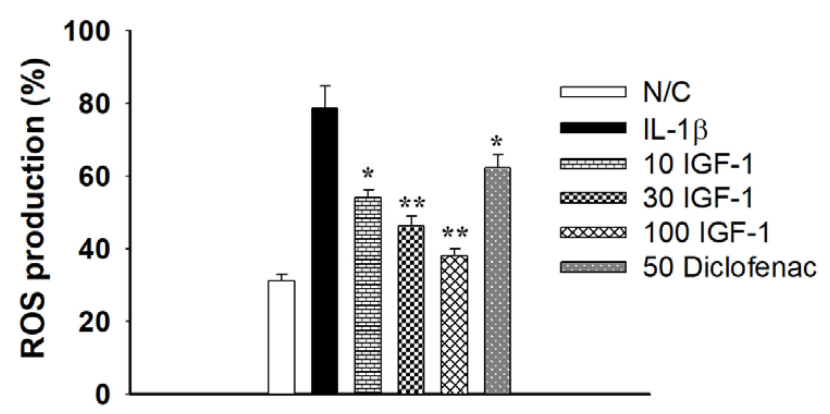

Figure I Effects of IGF-I on Chondrocytes during the development of OA induced by IL-I $\beta$ I0 ng/mL, (A) immunohistochemistry staining for the existence of MMP-I in vitro $(\times 200$, Scale bar $=200 \mu \mathrm{m})$, (B) Real-time PCR on mRNA for MMP-I3, MMP-3, MMP-I and TIMP-I, and (C) quantitative histogram of ROS production. Here, N/C= Normal control, IL-I $\beta=10 \mathrm{ng} / \mathrm{mL}$ IL-I $\beta$, 10 IGF-I = $10 \mathrm{ng} / \mathrm{mL} I$ GF-I, 30 IGF-I= $30 \mathrm{ng} / \mathrm{mL} I \mathrm{GF}-\mathrm{I}$, $100 \mathrm{IGF}-\mathrm{I}=100 \mathrm{ng} / \mathrm{mL} I \mathrm{GF}-\mathrm{I}$, and 50 Diclofenac= $50 \mu \mathrm{Ig} / \mathrm{mL}$ Diclofenac. Values are the mean \pm SD. $* p<0.05$, and $* * p<0.01$. 


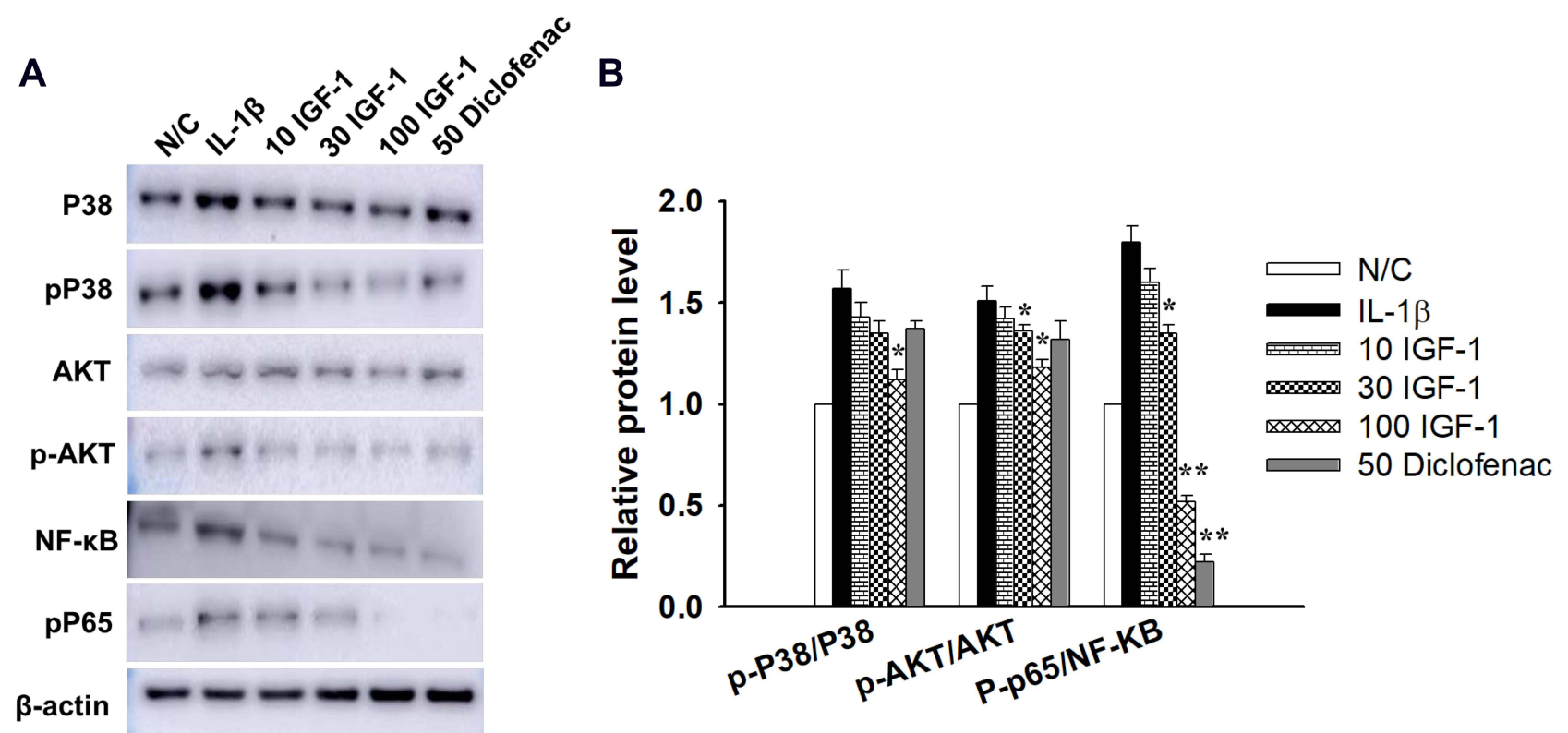

Figure 2 Effects of IGF-I on primary chondrocytes during IL-I $\beta$ stimulated specific signaling pathways, (A) Western blotting for the expression of p-P38/P38, p-Akt/Akt, $\mathrm{P}-\mathrm{p} 65 / \mathrm{NF}-\mathrm{\kappa B}$ and $(\mathrm{B})$ quantitative histogram in vitro. Values are the mean $\pm \mathrm{SD}$. ${ }^{*} p<0.05$, and $* * p<0.01$.

bax were increased in IL-1 $\beta$-stimulated chondrocytes. On the other hand, IGF-1 dose-dependently downregulated gene expression of TNF- $\alpha$, caspase 3 , and bax (Figure $3 \mathrm{~A}-\mathrm{C}$ ). This result indicates that IGF-1 prevents pro-inflammatory and pro-apoptotic activity in vitro.

\section{Macroscopic Evaluation in vivo}

A protective effect of IGF-1 was observed on the articular cartilage defects induced in OA rabbits. After 4 and 8 weeks, the OA group had damage to the cartilage characterized by a highly irregular surface; the surface area that went from whitish to reddish increased over time in the middle of the femoral condyle. By contrast, the normal control group had macroscopically regular cartilage with a smooth surface without any defects in the femoral condyle. The group that received IGF-1 showed recovery defect trochlear surface by fibrous tissue with a thin layer at 4 weeks and almost repaired at 8 weeks with proliferative fibrous tissue that was evident in the OA group. IGF-1 was associated with the new formation of hyaline cartilage such as tissue in a dose-dependent manner (Figure 4A and B).

\section{Intracellular ROS Production in vivo}

The effect of IGF-1 on intracellular ROS production in chondrocytes with osteoarthritis was investigated. Using CellROX Green reagent from a ROS detection kit, ROS secretion was analyzed after IGF-1 treatment in articular cartilage at 4 and 8 weeks. Intracellular ROS generation decreased after IGF-1 treatment than cartilage defect animals in a time- and dose-dependent manner (Figure 4C).

\section{MMPs and TIMP-I Gene Expression in vivo}

We next assessed the effects of IGF-1 on the expression of TIMP-1 and matrix metalloproteinases (MMPs) in femoral condyle cartilage. qRT-PCR was performed to detect the gene levels of TIMP-1, MMP-13, MMP-3, and MMP-1 in the defective cartilage after treatment with IGF-1 at 4 and 8 weeks. The IGF-1 group showed significant up-regulation of TIMP-1 gene expression and downregulation of MMP-13, MMP-3, and MMP-1 expression compared with the OA control group. The OA group was shown to have reduced TIMP-1 gene expression and increased MMP-13, MMP-3, and MMP1 levels (Figure 5A and B). Our results suggest that IGF-1 may prevent the progression of osteoarthritis by decreasing the MMPs and increasing the TIMP-1 genes expression.

\section{TNF- $\alpha$, Caspase- 3 and Bax in vivo}

Additional examination revealed that TNF- $\alpha$ (a proinflammatory factor) gene expression and the pro-apoptotic genes caspase 3 and bax were increased in the cartilage defect group. On the other hand, IGF-1 treatment dosedependently downregulated the expression of the TNF- $\alpha$, caspase 3, and bax genes (Figure $5 \mathrm{C}-\mathrm{E}$ ). This result indicates 

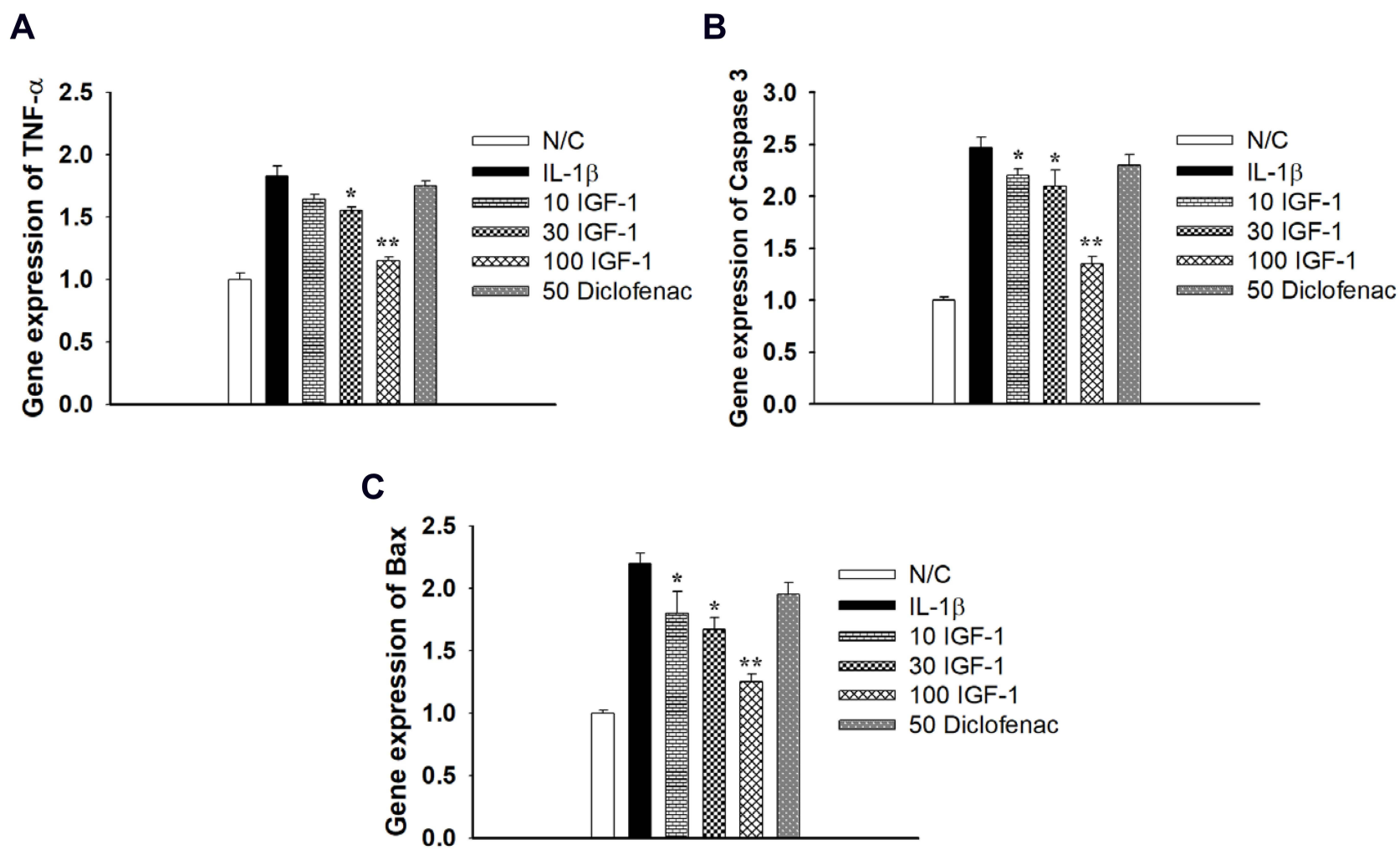

Figure 3 Effects of IGF-I on IL-I $\beta$ stimulated apoptosis in monolayer Chondrocytes in gene level of (A) TNF- $\alpha$, (B) Caspase 3 and (C) Bax gene expression in vitro. Values are the mean \pm SD. $* p<0.05$, and $* * p<0.01$.

that IGF-1 prevents pro-inflammatory and pro-apoptotic activity in vivo in the OA rabbit model, which is similar to the in vitro results.

\section{PI3K/Akt, NF-kB, and MAPK Signaling in vivo}

We observed in vivo protein expression of the PI3K/Akt, $\mathrm{NF}-\kappa \mathrm{B}$, and MAPK signaling pathways. The OA control group was shown to have higher expression of P-p65/ NF$\kappa \mathrm{B}, \mathrm{p}-\mathrm{P} 38 / \mathrm{P} 38$, and $\mathrm{p}-\mathrm{Akt} / \mathrm{Akt}$ when compared to the normal control group, and IGF-1 dose-dependently downregulated P-p65/NF- $\mathrm{BB}$, p-P38/P38, and p-Akt/Akt protein levels (Figure 6A-D).

\section{Histological Findings in vivo}

Abnormality of femoral condyle cartilage was evaluated by examining histological changes in the articular cartilage after IGF-1 treatment at 4 and 8 weeks. We considered the loss of glycosaminoglycan (GAG), lesions, scraping of the surface, and regeneration of new tissue. The OA control group had serious defects after 8 weeks compared to 4 weeks, with degraded condyle cartilage from the femoral trochlear surface, reduced chondrocytes (Figure 7A), and lesions GAG (Figure 7B) and Masson's trichrome staining also showed collagen damage in the articular cartilage area (Figure 7C). On the other hand, the IGF-1 group was protected from cartilage destruction; it had decreased chondrocyte-related irregularities, healthier expression of MMPs, and notably reduced condyle cartilage damage. The IGF-1 treated group was also observed to have new fibrous tissue in the defect area, as in the normal control group, and more collagen formation in the articular cartilage area, which was similar to the normal control on macroscopic investigation.

\section{Immunohistochemistry Analysis for MMP-I in vivo}

MMP-1 plays an important role in the development of osteoarthritis in condyle cartilage. In normal animals, fewer MMP-1-positive cells were observed in the 


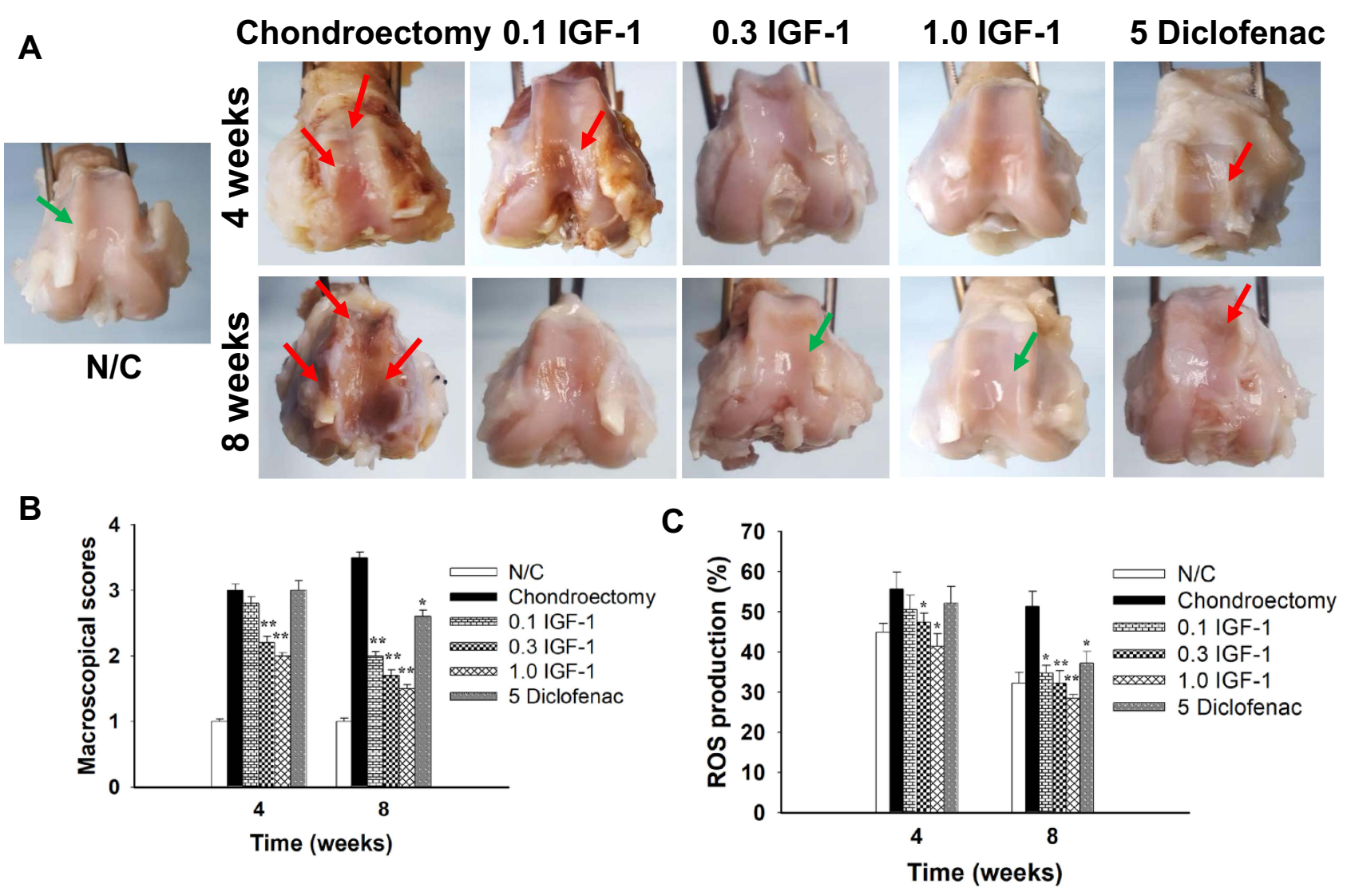

Figure 4 Effects of IGF-I on (A) macroscopic pictures and (B) macroscopic scores of rabbit's femoral condyles from cartilage damage after treatment with IGF-I at 4 and 8 weeks and $(\mathbf{C})$ quantitative histogram of ROS production in femoral condyles at 4 and 8 weeks in vivo. The Red arrow indicated articular cartilage destruction and the green arrow indicated reconstruction of femoral condyle surface by formation of new fibrous tissue. Here, N/C= Normal control, 0.1 IGF-I= I00 ng/mL IGF-I, 0.3 IGF-I= $300 \mathrm{ng} /$ $\mathrm{mL}$ IGF-I, I.0 IGF-I $=1 \mu \mathrm{g} / \mathrm{mL}$ IGF-I, and 5 Diclofenac $=5 \mathrm{mg} / \mathrm{mL}$ Diclofenac. Values are the mean $\pm \mathrm{SD} . *_{p}<0.05$, and $* * p<0.01$.

A

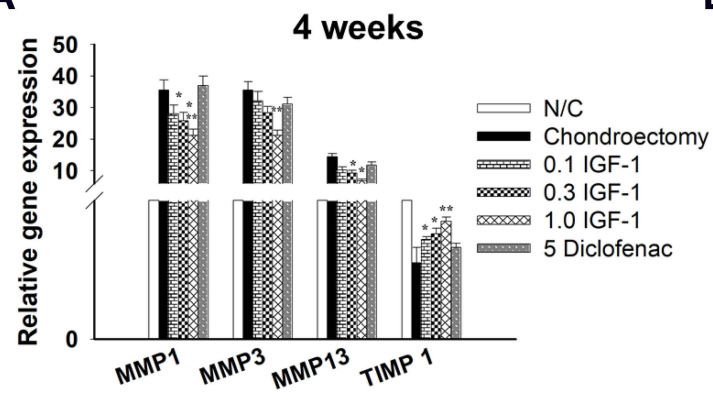

B

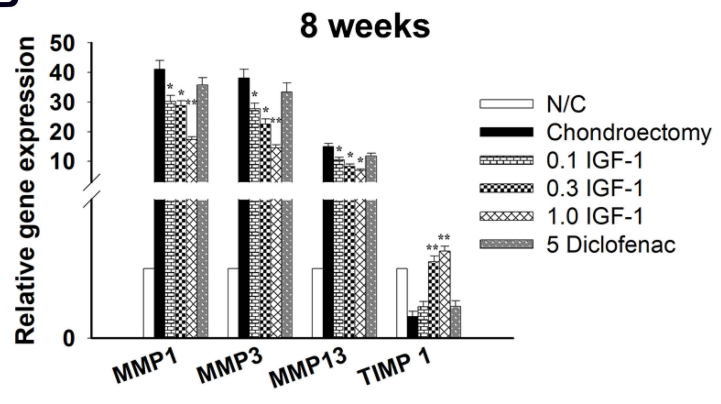

C

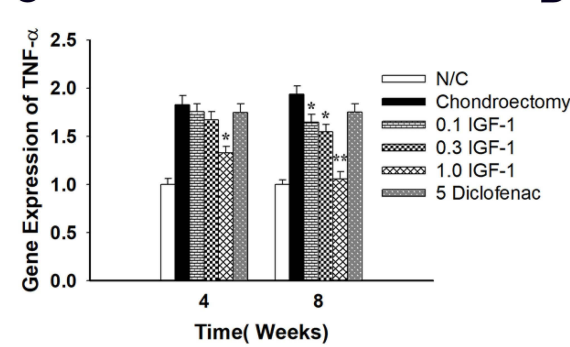

D

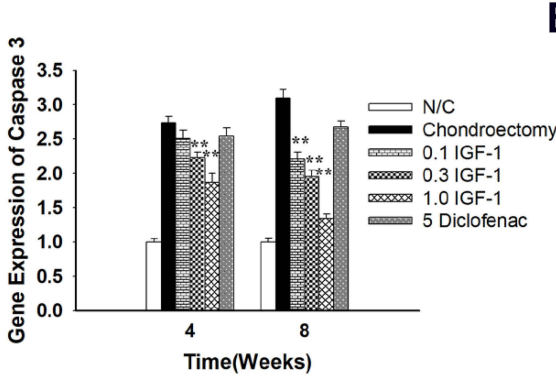

E

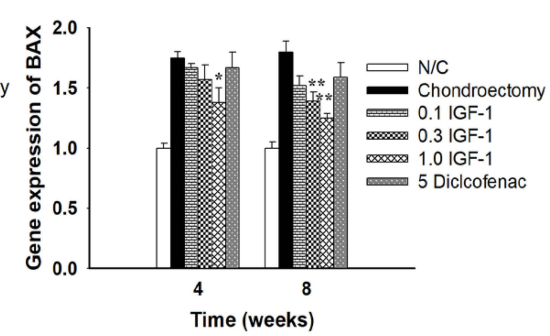

Figure 5 Effects of IGF-I on genes level of MMP-I3, MMP-3, MMP-I and TIMP-I in rabbit's articular cartilage at (A) 4 weeks, (B) 8 weeks after treatment and (C) TNF- $\alpha$, (D) Caspase 3, and (E) Bax gene expression in vivo by real-time PCR. Values are the mean \pm SD. $* p<0.05$, and $* * p<0.01$. 

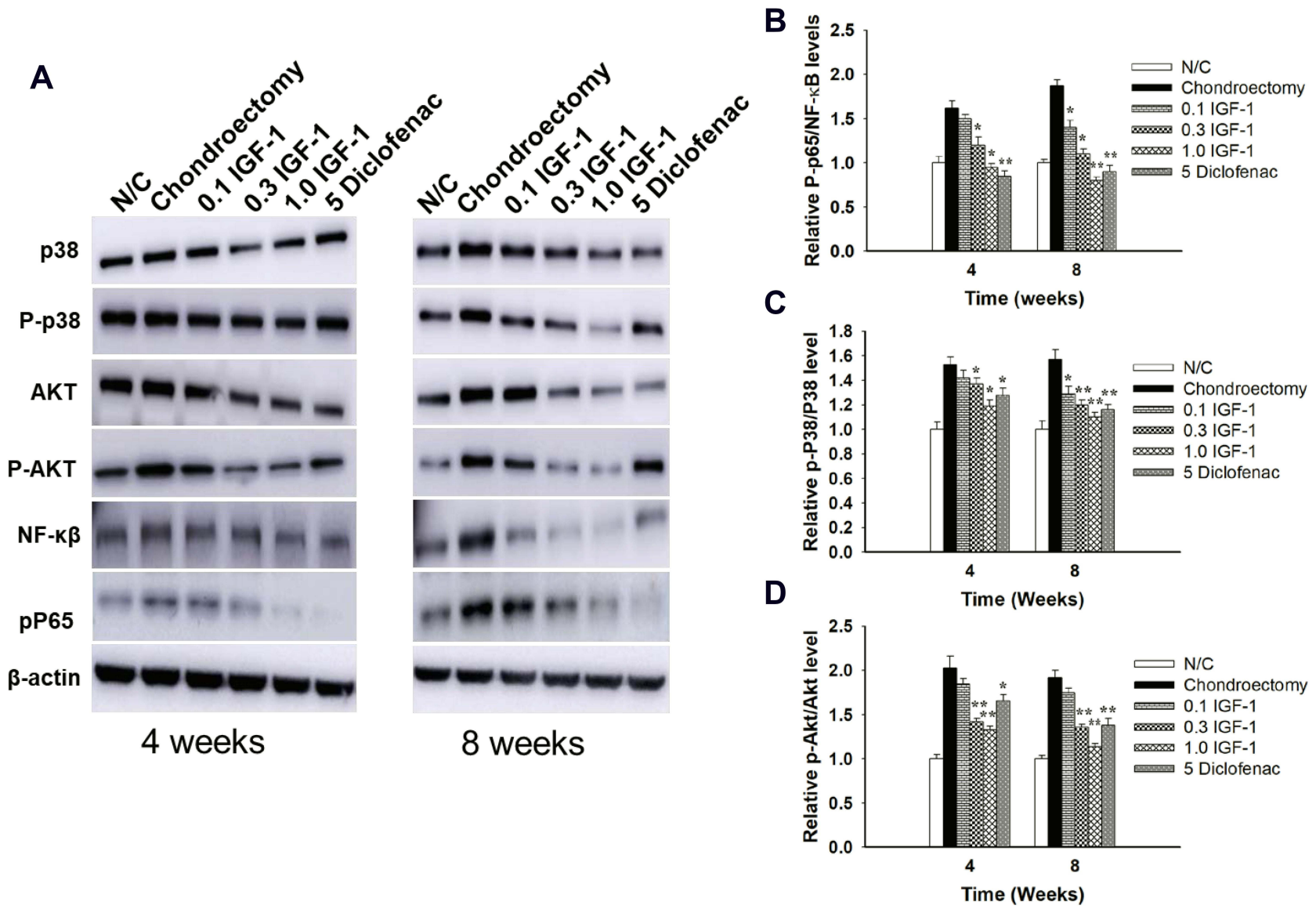

Figure 6 Effects of IGF-I on MAPKs, PI3K/Akt, NF-KB signaling pathways on rabbit's femoral condyles during cartilage damage (A) Western blotting for the expression of p-P38/P38, p-Akt/Akt, P-p65/NF-kB and quantitative histogram (B), (C) and (D) in vivo. Values are the mean \pm SD. ${ }^{*} p<0.05$, and $* * p<0.01$.

superficial and middle cartilage layer then were seen in the defect animals. In contrast, the disease control rabbit's condyle cartilage showed a significant number of MMP1-positive cells. Conversely, IGF-1 treatment was associated with less MMP-1-positive staining then the defect group in a dose-dependent manner and recovered from cartilage destruction (Figure 7D).

\section{Discussion}

In osteoarthritis, drug management is the first choice for treatment. IGF-1 has been shown to improve the renovation of tissue development. It helps in the recovery of large cartilage defects and aids in maintaining the balance between type II collagen and proteoglycans in the articular cartilage. ${ }^{34}$ IGF-1 exerts anti-apoptotic and anti-inflammatory effects in primary chondrocytes via regulation of the IL- $1 \beta$ cellular response and NF- $\mathrm{KB}$ signaling pathway. ${ }^{35}$ Many inflammatory diseases like osteoarthritis involve IL-1 $\beta$, which is known to stimulate TIMP-1 and MMPs in the articular cartilage in vitro. Two main families of enzymes are leading degenerative alterations in OA: MMPs, which facilitate type II collagen and matrix components of degeneration and TIMPs, which maintenance the activity of enzymes. ${ }^{36}$ Different MMPs subtypes are playing various roles in different stages of articular cartilage degradation during OA pathogen. The MMP-1 expression is severely enhanced in response to stimulation of TNF- $\alpha$ and interleukin (IL)-1; it reduces collagen in the ECM and causes cartilage destruction, playing a significant role in the OA disease process. ${ }^{37}$

MMP-13, a biochemical marker of collagenase for cartilage erosion and during the early stages of $\mathrm{OA}$ found in a high level in the cartilage matrix. ${ }^{38,39}$ TIMP-1 not only prevents the activated MMPs, but it also inhibits and delays the prototype of MMPs enzyme from changing into active types. $^{40}$ Our experimental study revealed that IGF-1 protected against IL-1 $\beta$-mediated chondrocyte disruption by preventing expression of MMPs, such as MMP-13, MMP3, and MMP-1 and enhancing TIMPs in vitro (Figure 1B). The results suggested that IGF-1 is involved in the prevention of chondrocyte-related pathological disorders by protecting 


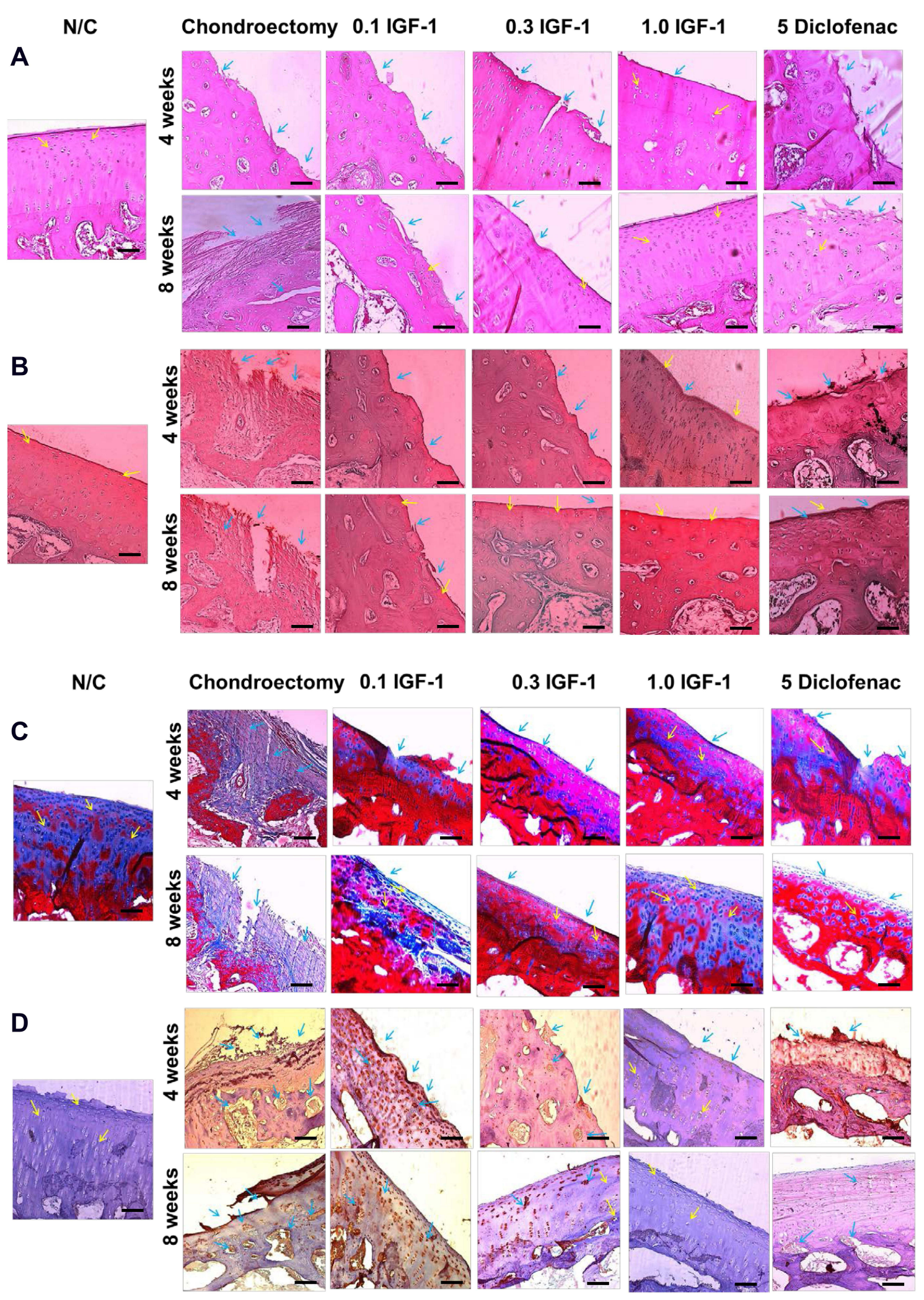

Figure 7 Effects of IGF-I on (A) hematoxylin-eosin staining (B) safranin $\mathrm{O}(\mathbf{C})$ masson's trichrome staining for the existence of the cartilage during the OA in rabbit femoral condyle after treatment of at 4 and 8 weeks and (D) immunohistochemistry staining for the existence of MMP-I in the cartilage at 4 and 8 weeks in vivo $(\times 200$, scale bar $=$ $200 \mu \mathrm{m})$. Yellow arrow indicated chondrocyte cell and blue arrow indicated erosion of condyle and positive MMP-I (IHC). 
from IL-1 $\beta$-mediated MMP expression, which is why we were inspired to perform our in vivo study. As we demonstrated, IGF-1 treatment allowed the cartilage to recover from structural damage dose- and time-dependently, thereby ameliorating OA progression, as shown by the histological study and the macroscopic appearance of the cartilage (Figures 4A, $\mathrm{B}$ and $7 \mathrm{~A}-\mathrm{C}$, and Supplementary Figure 2). However, after receiving the IGF-1, more chondrocytes $(\mathrm{H} / \mathrm{E})$, collagen (masson's stain) and proteoglycans (safranin O stain) were observed in the defect area at 8 weeks than 4 weeks by contrast the defect group show only a few cells over the time duration. So the IGF-1 showed the chondroprotective effect against articular cartilage degradation by regulation of collagen, proteoglycan and produce hyaline cartilage. After IL-1 $\beta$ induced OA in chondrocyte and cartilage rupture, the positive MMP-1 cells expressed high in the OA group than the normal control group and more proportion MMP-1 positive cells in 8 weeks than 4 weeks in particular cartilage ruptures group which means more collagen fibers decline and cartilage degradation. But after IGF-1 treatment in both in vitro and in vivo the MMP-1 positive cells significantly lower than the OA group in the dose and time-dependent (Figures 1A and 7D).

The OA-specific RNA component TIMP-1 was upregulated and MMP-1, MMP-3 and MMP-13 levels were down-regulated in rabbits following IGF-1 administration. This evidence strengthens the notion that IGF-1 protects against cartilage defects in the OA model (Figure 5A and $B)$. These studies are consistent with our in vitro investigational findings (Figure 1B). So, the current in vitro and in vivo results point to a role for IGF-1 in the prevention of chondrocyte degradation in articular cartilage. Various signaling pathways, such as the PI3K/Akt, NF- $\mathrm{BB}$, and MAPK pathways, have important roles in the metabolic and biomechanical pathways associated with the pathogenesis of OA, and IGF-1 has been shown to have anti-arthritis activity via PI3K/Akt, NF- $\kappa \mathrm{B}$, and MAPK signaling. ${ }^{13,41}$ OA-related pathogenesis is majorly orchestrated by NF- $\mathrm{B}$ signaling pathway, and several other studies have also shown that the pathogenesis is also mediated by $\mathrm{PI} 3 \mathrm{~K} / \mathrm{AKT}$ signaling via pro-inflammatory cytokines like IL-1 $\beta$. Upon binding of IL$1 \beta$ to its receptor, the membrane protein PI3K induces the phosphorylation of AKT and found to have synergistic effect on NF- $\kappa \mathrm{B}$ signaling. ${ }^{15,35}$ Our experimental data showed that IGF-1 significantly inhibited the stimulation of $N F-\kappa B$, as demonstrated by the reduction in $\mathrm{NF}-\kappa \mathrm{B}$ expression both in vitro and in vivo (Figures $2 \mathrm{~A}, \mathrm{~B}$ and $6 \mathrm{~A}-\mathrm{D}$ ). These results suggest that IGF-1 may decrease MMP expression by inhibiting the NF- $\kappa$ B signaling pathway.

Pro-inflammatory cytokines such as TNF- $\alpha$ and IL-1 have been associated with the pathogenesis of OA via activation of the P38 (MAPK) intracellular signaling pathway. ${ }^{42-44}$ Phosphorylation of MAPKs such as p38 and ERK is known to be upregulated in arthritis when compared to normal cartilage. $^{45}$ Our results showed that IGF-1 administration significantly decreases P38 levels in an osteoarthritis animal model as well as in chondrocytes dose-dependently. Our findings clearly indicate that IGF-1 plays a vital role in the MAPK signaling pathway via regulation of P38 to prevent OA. The PI3K/AKT signaling pathway also plays a major role in OA. Phosphorylated Akt and PI3K act as persistence signals in TNF- $\alpha$ - associated apoptosis. ${ }^{46}$ Our experimental data show that IGF-1 administration down-regulated p-AKT expression in a dose-dependent manner, whereas IL-1 $\beta$ treatment up-regulated the expression of p-AKT in vitro. Furthermore, a cartilage damage model was also shown to have upregulation of p-AKT (Figures 2A, B and 6A-D). Therefore, our results indicate that IGF-1 protects against the progression of inflammatory intermediaries in OA which are involved in moderate suppression of MAPK cascades or PI3K/AKT signaling, and thereby inhibits the activation of $\mathrm{NF}-\kappa \mathrm{B}$. A scheme of diagram showed that anti-osteoarthritis effect of IGF-1 (Figure 8). Apoptosis may involve to the loss of chondrocyte and following degeneration of cartilage. ${ }^{31}$ The family of caspases that are dangerous mediators of the apoptotic pathway. The Previous study revealed that IGF-1 prevents chondrocytes apoptosis following cartilage damage. ${ }^{30}$ Our study also showed that IGF-1 prevents cartilage degradation and apoptosis with significant anabolic growth function (Figures $3 \mathrm{~A}-\mathrm{C}$ and $5 \mathrm{C}-\mathrm{E}$ ). Chondrocyte apoptosis in the articular cartilage owing to intracellular ROS facilitate degradation and damage of the ECM. ${ }^{47,48}$ ROS-related cell death is inhibited in chondrocytes by IGF1, which rescues the articular cartilage from ROS-stimulated cytotoxicity. ${ }^{49}$ Our investigational study agrees with these findings. Furthermore, these results show that IGF-1 administration significantly reduced ROS production in chondrocytes in vitro and in vivo (Figures $1 \mathrm{C}$ and $4 \mathrm{C}$ ) and annexin $\mathrm{V} / \mathrm{PI}$ results showed that IGF-1 inhibits IL-1 $\beta$ induced apoptosis in chondrocytes (Supplementary Figure 1).

\section{Conclusion}

In conclusion, we established the healing effects of IGF-1 in chondrocytes and a rabbit model against osteoarthritis. IGF-1 inhibited the NF- $\kappa$, p38 (MAPK), and PI3K/AKT 


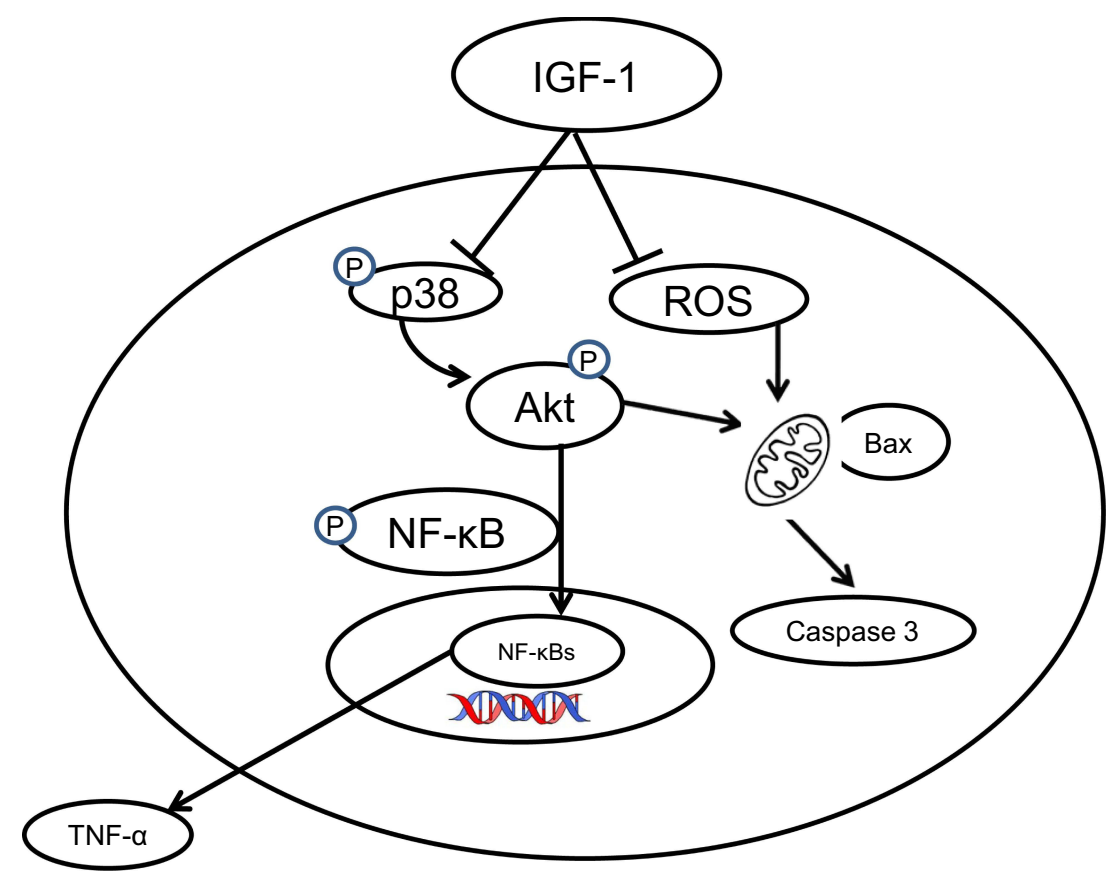

Figure 8 An overall schematic diagram of this study clearly indicates that IGF-I inhibits osteoarthritis activity via the PI3K/Akt, NF- $\kappa B$, and MAPK signaling pathways. $(-1$ indicate inhibitory pathways, $\rightarrow$ indicate stimulatory pathways).

signaling pathways, thereby preventing MMPs expression during OA pathogen, and also balanced collagen type II and proteoglycan and formation of hyaline cartilage. Therefore, in articular cartilage lesions, Intra-articular injection of IGF-1 leading a better tactic for effective and efficient therapy. So, our study revealed that IGF-1 could be a potential therapeutic mediator for the management of cartilage damage related to OA. However, our initial finding only on animal and cell levels of anti-OA, further needed to clinical implementation evaluation.

\section{Acknowledgments}

This research was supported by a grant of the Korea Health Technology R\&D Project through the Korea Health Industry Development Institute (KHIDI), funded by the Ministry of Health \& Welfare, Republic of Korea. (grant number: HI18C0661).

\section{Disclosure}

The authors report no conflicts of interest in this work.

\section{References}

1. Felson DT. Epidemiology of hip and knee osteoarthritis. Epidemiol Rev. 1988;10:1-28. doi:10.1093/oxfordjournals.epirev.a036019.

2. Wuelling M, Vortkamp A. Chondrocyte proliferation and differentiation. Endocr Dev Karger Publishers. 2011;21:1-11. doi:10.1159/000328081.
3. Messner K, Gillquist J. Cartilage repair: a critical review. Acta Orthop Scand. 1996;67(5):523-529. doi:10.3109/17453679608 996682.

4. Wojdasiewicz P, Poniatowski ŁA, Szukiewicz D. The role of inflammatory and anti-inflammatory cytokines in the pathogenesis of osteoarthritis. Mediators Inflamm. 2014;2014:561459. doi:10.1155/ 2014/561459

5. Chen S, Zhang L, Xu R, et al. TheBDKRB2+ 9/-9 Polymorphisms influence pro-inflammatory cytokine levels in knee osteoarthritis by altering TLR-2 Expression: clinical and in vitro Studies. Cell Physiol Biochem. 2016;38(3):1245-1256. doi:10.1159/000443072

6. Zhang G, Sun Y, Wang Y, et al. MiR-502-5p inhibits IL-1 $\beta$-induced chondrocyte injury by targeting TRAF2. Cell Immunol. 2016;302:50-57. doi:10.1016/j.cellimm.2016.01.007

7. Larsson S, Englund M, Struglics A, et al. Interleukin-6 and tumor necrosis factor alpha in synovial fluid are associated with progression of radiographic knee osteoarthritis in subjects with previous meniscectomy. Osteoarthritis Cartilage. 2015;23(11):1906-1914. doi:10.1016/j.joca.2015.05.035

8. Rowan AD, Litherland GJ, Hui W, et al. Metalloproteases as potential therapeutic targets in arthritis treatment. Expert Opin Ther Targets. 2008;12(1):1-18. doi:10.1517/14728222.12.1.1

9. Dean DD, Martel-Pelletier J, Pelletier JP, et al. Evidence for metalloproteinase and metalloproteinase inhibitor imbalance in human osteoarthritic cartilage. J Clin Invest. 1989;84(2):678-685. doi:10.1172/JCI114215

10. Mengshol JA, Vincenti MP, Coon CI, et al. Interleukin-1 induction of collagenase 3 (matrix metalloproteinase 13) gene expression in chondrocytes requires p38, c-Jun N-terminal kinase, and nuclear factor $\kappa \mathrm{B}$ : differential regulation of collagenase 1 and collagenase 3. Arthritis Rheum. 2000;43(4):801-811. doi:10.1002/1529-0131(200004) $43: 4<801:$ :aid-anr 10>3.0.CO;2-4

11. Vincenti MP, Brinckerhoff CE. Transcriptional regulation of collagenase (MMP-1, MMP-13) genes in arthritis: integration of complex signaling pathways for the recruitment of gene-specific transcription factors. Arthritis Res. 2002;4(3):157-164. doi:10.1186/ar401 
12. Liacini A, Sylvester J, Li WQ, et al. Inhibition of interleukin-1-stimulated MAP kinases, activating protein-1 (AP-1) and nuclear factor kappa B (NF- $\mathrm{B})$ transcription factors down-regulates matrix metalloproteinase gene expression in articular chondrocytes. Matrix Biol. 2002;21(3):251-262. doi:10.1016/s0945-053x(02)00007-0

13. Zheng X, Xia C, Chen Z, et al. Requirement of the phosphatidylinositol 3-kinase/Akt signaling pathway for the effect of nicotine on interleukin-1beta-induced chondrocyte apoptosis in a rat model of osteoarthritis. Biochem Biophys Res Commun. 2012;423(3):606-612. doi:10.1016/j.bbrc.2012.06.045

14. Loeser RF, Erickson EA, Long DL. Mitogen-activated protein kinases as therapeutic targets in osteoarthritis. Curr Opin Rheumatol. 2008;20(5):581-586. doi:10.1097/ BOR.0b013e3283090463

15. Xie L, Xie H, Chen $\mathrm{C}$, et al. Inhibiting the PI3K/AKT/NF- $\kappa$ B signal pathway with nobiletin for attenuating the development of osteoarthritis: in vitro and in vivo studies. Food Funct. 2019;10 (4):2161-2175. doi:10.1039/c8fo01786g

16. Marcu KB, Otero M, Olivotto E, et al. NF- $\kappa B$ signaling: multiple angles to target OA. Curr Drug Targets. 2010;11(5):599-613. doi:10.2174/138945010791011938

17. Fajardo M, Di Cesare PE. Disease-modifying therapies for osteoarthritis. Drugs Aging. 2005;22(2):141-161. doi:10.2165/ 00002512-200522020-00005

18. Singh R, Akhtar N, Haqqi TM. Green tea polyphenol epigallocatechi3-gallate: inflammation and arthritis. Life Sci. 2010;86(25-26):907-918. doi:10.1016/j.1fs.2010.04.013

19. Ishihara K, Nakayama K, Akieda S, et al. Simultaneous regeneration of full-thickness cartilage and subchondral bone defects in vivo using a three-dimensional scaffold-free autologous construct derived from high-density bone marrow-derived mesenchymal stem cells. Tissue Eng. 2014;9:98. doi:10.1186/s13018-014-0098-z

20. Brittberg M, Lindahl A, Nilsson A, et al. Treatment of deep cartilage defects in the knee with autologous chondrocyte transplantation. Tissue Eng. 1994;331(14):889-895. doi:10.1056/NEJM199410063311401

21. Mandl EW, Van Der Veen SW, Verhaar JA, et al. Serum-free medium supplemented with high-concentration FGF2 for cell expansion culture of human ear chondrocytes promotes redifferentiation capacity. Tissue Eng. 2002;8(4):573-580. doi:10.1089/107632702760240490

22. McCarthy TL, Centrella M. Local IGF-I expression and bone formation. Growth Horm IGF Res. 2001;11(4):213-219. doi:10.1054/ghir.2001.0236

23. Morales TI, Hascall VC. Factors involved in the regulation of proteoglycan metabolism in articular cartilage. Arthritis Rheum. 1989;32 (10):1197-1201. doi:10.1002/anr.1780321003

24. Middleton J, Tyler JA. Upregulation of insulin-like growth factor I gene expression in the lesions of osteoarthritic human articular cartilage. Ann Rheum Dis. 1992;51(4):440-447. doi:10.1136/ard.51.4.440

25. Verschure PJ, Van Noorden CJ, Marle JV, et al. Articular cartilage destruction in experimental inflammatory arthritis: insulin-like growth factor-1 regulation of proteoglycan metabolism in chrondrocytes. Histochem J. 1996;28(12):835-857. doi:10.1007/ BF02331388

26. Fernandes JC, Martel-Pelletier J, Pelletier JP. The role of cytokines in osteoarthritis pathophysiology. Biorheology. 2002;39(1,2):237-246.

27. Shakibaei M, Seifarth C, John J, et al. Igf-I extends the chondrogenic potential of human articular chondrocytes in vitro: molecular association between Sox9 and Erk1/2. Biochem Pharmacol. 2006;2 (11):1382-1395. doi:10.1016/j.bcp.2006.08.022

28. Hickey DG, Frenkel SR, Di PC. Clinical applications of growth factors for articular cartilage repair. Am J Orthop. 2003;32(2):70-76.

29. Oh CD, Chun JS. Signaling mechanisms leading to the regulation of differentiation and apoptosis of articular chondrocytes by insulin-like growth factor-1. J Biol Chem. 2003;278(38):36563-36571. doi:10.1074/jbc.M304857200
30. D'Lima DD, Hashimoto S, Chen PC, et al. Prevention of chondrocyte apoptosis. J Bone Joint Surg Am. 2001;83:S25-26. doi:10.2106/ 00004623-200100021-00006

31. Lo MY, Kim HT. Chondrocyte apoptosis induced by collagen degradation: inhibition by caspase inhibitors and IGF-1. J Orthop Res. 2004;22(1):140-144. doi:10.1016/S0736-0266(03)00117-7

32. Pelletier JP, Fernandes JC, Brunet J, et al. In vivo selective inhibition of mitogen-activated protein kinase kinase $1 / 2$ in rabbit experimental osteoarthritis is associated with a reduction in the development of structural changes. Arthritis Rheum. 2003;48(6):1582-1593. doi:10.1002/art.11014

33. Mankin HJ, Dorfman H, Lippiello L, et al. Biochemical and metabolic abnormalities in articular cartilage from osteo-arthritic human hips: II. correlation of morphology with biochemical and metabolic data. J Bone Joint Surg Am. 1971;53(3):523-537. doi:10.2106/ 00004623-197153030-00009

34. Fortier L, Mohammed HO, Lust G, et al. Insulin-like growth factor-I enhances cell-based repair of articular cartilage. $J$ Bone Joint Surg Br. 2002;84(2):276-288. doi:10.1302/0301620x.84b2.11167

35. Montaseri A, Busch F, Mobasheri A, et al. IGF-1 and PDGF-bb suppress IL-1 $\beta$-induced cartilage degradation through downregulation of NF- $\mathrm{KB}$ signaling: involvement of Src/PI-3K/AKT pathway. PLoS One. 2011;6(12):e28663. doi:10.1371/journal. pone.0028663.

36. Roughley PJ. The structure and function of cartilage proteoglycans. Eur Cell Mater. 2006;12:92-101. doi:10.22203/ecm.v012a11

37. Stetler-Stevenson WG, Yu AE. Proteases in invasion: matrix metalloproteinases. Seminr Cancer Biol. 2001;11(2):143-152. doi:10.1006/scbi.2000.0365

38. Mitchell PG, Magna HA, Reeves LM, et al. Cloning, expression, and type II collagenolytic activity of matrix metalloproteinase-13 from human osteoarthritic cartilage. J Clin Invest. 1996;97(3):761-768. doi:10.1172/JCI118475

39. Hernandez-Barrantes S, Bernardo M, Toth M, et al. Regulation of membrane type-matrix metalloproteinases. Semin Cancer Biol. 2002;12(2):131-138. doi:10.1006/scbi.2001.0421

40. Hulboy DL, Rudolph LA, Matrisian LM. Matrix metalloproteinases as mediators of reproductive function. Mol Hum Reprod. 1997;3 (1):27-45. doi:10.1093/molehr/3.1.27

41. Lu S, Xiao X, Cheng M. Matrine inhibits IL- $1 \beta$-induced expression of matrix metalloproteinases by suppressing the activation of MAPK and NF- $\kappa \mathrm{B}$ in human chondrocytes in vitro. Int J Clin Exp Pathol. 2015;8(5):4764-4772.

42. Rouse J, Cohen P, Trigon S, et al. A novel kinase cascade triggered by stress and heat shock that stimulates MAPKAP kinase-2 and phosphorylation of the small heat shock proteins. Cell. 1994;78 (6):1027-1037. doi:10.1016/0092-8674(94)90277-1

43. Bhowmick NA, Zent R, Ghiassi $M$, et al. Integrin $\beta 1$ signaling is necessary for transforming growth factor- $\beta$ activation of p38MAPK and epithelial plasticity. J Biol Chem. 2001;276(50):46707-46713. doi:10.1074/jbc.M106176200

44. Yosimichi G, Nakanishi T, Nishida T, et al. CTGF/Hes24 induces chondrocyte differentiation through a p38 mitogen-activated protein kinase (p38MAPK), and proliferation through a p44/42 MAPK/extracellular-signal regulated kinase (ERK). Eur J Biochem. 2001;268 (23):6058-6065. doi:10.1046/j.0014-2956.2001.02553.x

45. Boileau C, Martel-Pelletier J, Brunet J, et al. PD-0200347, an $\alpha 2 \delta$ ligand of the voltage gated calcium channel, inhibits in vivo activation of the Erk1/2 pathway in osteoarthritic chondrocytes: a $\mathrm{PKC} \alpha$ dependent effect. Ann Rheum Dis. 2006;65(5):573-580. doi:10.1136/ ard.2005.041855

46. Mendoza-Milla C, Rodríguez CM, Alarcón EC, et al. NF- $\kappa \mathrm{B}$ activation but not PI3K/Akt is required for dexamethasone dependent protection against TNF- $\alpha$ cytotoxicity in L929 cells. FEBS Lett. 2005;579(18):3947-3952. doi:10.1016/j.febslet.2005.05.081 
47. Henrotin YE, Bruckner P, Pujol JP. The role of reactive oxygen species in homeostasis and degradation of cartilage. Osteoarthr Cartil. 2003;11(10):747-755. doi:10.1016/s1063-4584(03)00150-x

48. Lee HG, Yang JH. PCB126 induces apoptosis of chondrocytes via ROS-dependent pathways. Osteoarthritis Cartilage. 2012;20 (10):1179-1185. doi:10.1016/j.joca.2012.06.004
49. Jallali N, Ridha H, Thrasivoulou C, et al. Modulation of intracellular reactive oxygen species level in chondrocytes by IGF-1, FGF, and

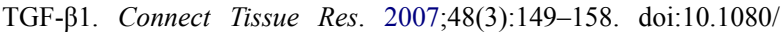
03008200701331516

\section{Publish your work in this journal}

The Journal of Inflammation Research is an international, peerreviewed open-access journal that welcomes laboratory and clinical findings on the molecular basis, cell biology and pharmacology of inflammation including original research, reviews, symposium reports, hypothesis formation and commentaries on: acute/chronic inflammation; mediators of inflammation; cellular processes; molecular mechanisms; pharmacology and novel anti-inflammatory drugs; clinical conditions involving inflammation. The manuscript management system is completely online and includes a very quick and fair peerreview system. Visit http://www.dovepress.com/testimonials.php to read real quotes from published authors. 